\title{
Comparing The Effect of Virtual and Face-to-Face Education on Learning Motivation and Procrastination in Elementary School Students During the Coronavirus Pandemic (COVID-19)
}

\author{
Majid Yousefi Afrashteh*, Mohadeseh Koohneshin Seighalani \\ 1. University of Zanjan, Zanjan, Iran. \\ 2. Payame Noor University, Qazvin Center, Qazvin, Iran. \\ * Corresponding author's Email: yousefi@znu.ac.ir
}

\begin{abstract}
In the current situation, due to the spread of the coronavirus, the use of virtual education has expanded. The aim of this study is to compare the learning motivation and academic procrastination of students with face-to-face and virtual education in an applied and quasi-experimental method. The study population is all primary school students in Somehsara, city, Iran in the first half of the academic year 13001400 , from which 30 girls and 30 boys are selected by purposive sampling from rural areas. Data are collected through David Tuckman (2001), Academic Procrastination Questionnaire and Power, China and Objective Learning Motivation (2005). The results of analysis of covariance with spss-26 software show that the mean of both face-to-face and virtual groups in the pretest is equal. However, post-test type of training on learning motivation $(\mathrm{F}=54.24)$ and procrastination $(\mathrm{F}=42.44)$ is significant at the error level of less than 0.01 . However, gender as a second independent variable and in interaction with the independent variable of education has no effect on academic motivation and academic procrastination. Based on these results, it can be said that although the use of virtual education is inevitable, but its long-term use reduces academic motivation and increases the procrastination of elementary school students.

Keywords: Learning motivation, academic procrastination, face-to-face education, virtual education, students.
\end{abstract}

\section{Introduction}

Education is known as one of the most important and challenging issues in human life and its quality determines the quality of individual and collective life (samavi, javidi, kazemi and baghouli, 2020). The sudden outbreak of a deadly coronavirus has affected the whole world. This challenges the education system around the world, forcing teachers to set up an online education network (Dhawan, 2020). Virtual education is the delivery of technology education to students who have been separated from their teachers (Molnar et al., 2019). An appropriate, secure, and cost-effective alternative to a virtual education system than traditional education is needed for training in such situations (Santamaría et al. 2020). Virtual learning environment is a unique environment with e-learning tools for teaching and learning (DuQuette, 2017; Azlan et al., 2020). No educational approach can replace formal face-to-face education because of the student's direct interaction with the teacher. Virtual education is an educational change from the traditional method to modern approach outside the classroom at any time and place (Illich, 1971; Singh \& Thurman, 2019 and Mishra, Gupta, Shree, 2020). However, students prefer faceto-face instruction when faced with difficult topics such as math and science, as web-based math lessons are more problematic than other disciplines (Jaggers, 2014). In online learning, students are easily distracted by various online attractions (Tsai \& Shen, 2009). 
One of the variables in e-learning that may be different from face-to-face training is learning motivation. Motivation is a complex psychological process that includes many aspects such as cognition, behavior, emotions, decision-making process and biological aspects (Gonzalez, 2008; Marshall, 2010; and Wang and Ryan, 2016). Students who are highly motivated to learn tend to search for and obtain information about them (Colquitt, Lepin and Noe, 2000; Klassen and Tze, 2014). Acquiring knowledge may stimulate feelings of curiosity and interes; it strengthens the learning motivation (Murayama, FitzGibbon, \& Sakaki, 2019). Motivation may be increased through exposure to new knowledge, especially if the new knowledge is surprising or useful (Fletcher et al., 2001; Harackiewicz, 2012; Mezirow, 2000). Motivation can play an important role in promoting students' academic achievement (Samavi, Ebrahimi and Javdan, 2017). One way to increase students' motivation to learn is competition (Burguillo, 2010; Huang, Huang \& Tschopp, 2010; Park, Lee \& Chung, 2016). Motivation theory proposes two types of intrinsic and extrinsic motivation (Desi, 1976). Motivational factors, feelings of isolation, and lack of social support for a web-based learning environment make learning in virtual education more challenging (Kim et al., 2014).

Another variable that may have changed in e-learning is procrastination. Procrastination is a delay, intentional delay, or a deliberate decision to drop out of work (Islas, 2018). Procrastination is an emotional disorder that causes significant harm to a person. But it rarely stops the individual (Ellis \& Knaus, 1979). Procrastination is often inversely related to the variables of self-esteem, self-efficacy and motivation. In general, academic procrastination seems to be associated with health side effects such as anxiety, depression, sleep hygiene and emotional health, and poor academic performance (Hen \& Goroshit, 2012; Conception, 2020; \& Ziegler and Opdenakker, 2018). Students' academic procrastination is negatively related to self-esteem, academic achievement, and conscientiousness (Won and $\mathrm{Yu}, 2018$ ). Academic procrastination is positively associated with smartphone addiction and neuropathy ( $\mathrm{Li}, \mathrm{Gao}$ and $\mathrm{Xu}, 2020$ ). Procrastination is the way people deal with the fear of making mistakes and failures, lack of self-confidence in doing homework, beyond mind-reading and daydreaming (Basco, 2009; Boice, 1996).

Moradi et al (2020) show that the virtual education method has occurred from the 1990s onwards at the same time as the globalization of the Internet. According to research by Wenzlau (2019), virtual education has increased significantly in recent years. However, there is no research on online teaching methods and how to address the individual needs of students in the virtual environment. Liu (2020) has shown that if students show stronger learning motivations, they will have better learning outcomes. In the study of Kljajic and Gaudreau (2018), students who have been moivated more than their peers, achieve higher score than their peers.

With these problems and challenges of e-learning and the status of modern education, which includes technology usage during the period of Covid 19 disease, especially for elementary students, the limitation of facilities is an important issue. Therefore, the main purpose of this study is the difference between learning motivation and academic procrastination of elementary students in face-to-face and virtual education. 


\section{Material and Methods}

In terms of purpose, the method of this research is applied and in terms of data collection is quasiexperimental. So that two groups of students are designated as experimental and control groups. The experimental group is exposed to virtual training for one semester, and the control group is exposed to conventional face-to-face training with the same extent. Before starting their studies, both groups complete academic procrastination and learning motivation questionnaires as a pre-test and at the end, and they responded the same questionnaires as a post-test. The statistical population of this study is all primary school students in the city of Soomehsara, Iran in the first semester of the academic year 13991400. Among them, 60 students from rural areas are selected by purposive sampling ( 30 people in each group). Each group consists of 15 girls and 15 boys, of whom 30 students experience face-to-face training, and the rest of them experience virtual training. The e-learning group is a sample of elementary students who have access to the internet, and face-to-face group consists of students who have face-toface training for internet access limitation in their area. It should be noted that the members of both groups are equal in family economic status, previous academic performance, educational facilities and parents' education. The only difference between the two groups is the type of their education (virtual and in-person). Prior to the students' participation, due to their young age, the objectives of the research and the executive process and the voluntary nature of the participation were explained to the parents and their informed consent was obtained for their children's participation in the research. Parents were assured that the information received would be kept confidential.

\section{Instruments}

The Academic Procrastination Questionnaire: this Questionnaire was developed by Tuckman (1991). The Takman Procrastination Scale in Iran is translated by Bayat Moqaddas (2003) and its standardization and reliability are .73 on the students of Roodehen Azad University. Each item in the Likert scale is four degrees from 1 to 4 . Tuckman (1991) report a reliability coefficient with Cronbach's alpha in the form of a 16-item single-item substance of .86. A high score indicates more academic procrastination. The reliability of this questionnaire in the present study is .88 by retesting.

Tuan, Chin \& Shieh' Learning Motivation Questionnaire (2005): This questionnaire is introduced by Power, China and Object in 2005. Cronbach's alpha of the questionnaire components is ranged from .70 to .89 . Findings of this study indicate the validity and reliability of the test. The questionnaire has 35 items and is designed on a 5-point Likert scale and includes components of self-efficacy, active learning strategies, learning value, performance goal, success goal and motivation of learning environment. The higher the score, the more motivated the student is. The validity of this questionnaire in the present study is obtained by retesting .79 . 


\section{Results}

In this section, first descriptive statistics include the minimum value, maximum value, mean and standard deviation of participants' scores in every research variable (learning motivation and academic procrastination) by two groups (first group: face-to-face and second group: Virtual education) have been reported. In the inferential analysis section, first the analysis assumptions are reviewed and reported and then the research hypotheses are tested. In testing the research hypotheses, covariance analysis with SPSS software version 23 is used.

Table 1. Descriptive statistics for learning motivation and procrastination in two groups

\begin{tabular}{|c|c|c|c|c|c|}
\hline \multirow{2}{*}{ Group } & & \multicolumn{2}{|c|}{ Learning motivation } & \multicolumn{2}{|c|}{ Procrastination } \\
\cline { 2 - 6 } & \multirow{2}{*}{ Phase } & Mean & Mean & SD \\
\hline \multirow{2}{*}{ Face-to-face } & pre & 109.30 & 12.03 & 43.30 & 6.13 \\
\cline { 2 - 6 } & post & 112.74 & 11.92 & 42.12 & 5.94 \\
\hline \multirow{2}{*}{ Virtual } & pre & 102.95 & 10.76 & 51.31 & 6.10 \\
\cline { 2 - 6 } & post & 91.20 & 12.10 & 6.10 & \\
\hline
\end{tabular}

Descriptive information for pre-test and post-test of learning motivation and procrastination are divided into two groups in Table 1. Learning Motivation' mean in the face-to-face group in pre-test from 112.74 has reached to 109.30. But in the virtual group, the pre-test's mean is 102.95 , which reaches 91.20 in the post-test and incidentally shows a decrease in motivation. Procrastination's mean in the face-to-face group in pre-test from 43.30 has reached to 42.12 . But in the virtual group, the average of the pre-test is 44.10, which reached 51.31 in the post-test, which shows an increase in procrastination.

With an independent variable with two levels (face-to-face and non-face-to-face training) and two dependent variables and the existence of a pretest for each of the dependent variables in this study, the statistical analysis method is univariate analysis of covariance. Therefore, to test the two general hypotheses of the research, two univariate analysis of covariance are used to remove the effect of covariance specifically from its dependent. A covariance analysis is reported for both hypotheses.

In order to check the normality in this study, the skewness index is used. For a perfectly symmetric distribution the skewness is zero and for an asymmetric distribution with skewness towards higher values the skewness is positive, and for an asymmetric distribution with skewness towards smaller values the skewness value is negative. If the amount of skewness is in the range of 1- to 1, the distribution is completely normal, and if it is in the range of 2- to 2, the distribution has a slight skew and statistical analysis is still without problems. Leaning index for learning motivation in pre-test of face-to-face training group value is -0.53 ; For academic procrastination in the pre-test of the face-to-face education group, the value is 0.22 and in the virtual group the Leaning motivation's pre-test is -0.06 and for academic procrastination is 0.09 , which is between -1 to +1 . Therefore, the assumption of normality has been verified for the research variables. Another important assumption of analysis of covariance is the homogeneity of variance, which is tested and confirmed by Levin test for each of the hypotheses $(\mathrm{p}>0.05)$.

The results of analysis of covariance for the effect of the independent variable (education) on the dependent variable of learning motivation are reported in Table 2. 
Table 2. Analysis of covariance to investigate the effect of education on learning motivation

\begin{tabular}{|c|c|c|c|c|c|c|}
\hline Source & SS & df & MS & F & $p$ & Effect size \\
\hline Pre test & 1160.99 & 1 & 1160.99 & 41.69 & .001 & .57 \\
\hline Education & 1404.04 & 1 & 1404.04 & 54.24 & .001 & .67 \\
\hline Gender & 89.15 & 1 & 89.15 & 1.95 & .21 & .11 \\
\hline Interaction & 28.69 & 1 & 28.69 & 1.30 & .30 & .08 \\
\hline Error & 436.74 & 27 & 16.17 & & & \\
\hline Total & 3119 & 30 & & & & \\
\hline
\end{tabular}

As can be seen from Table 2, the pre-test of learning motivation with a value of $F=41.69$ is significant at an error level of less than 0.01. Also, the effect of independent variable, education, on post-test of learning motivation has become significant $(\mathrm{F}=54.24)$. In fact, after removing the pre-test effect, the independent variable had an effect on the dependent. But gender does not have a significant effect on learning motivation. The interactive effect is also not significant. According to this finding, the first hypothesis of the research is confirmed, but gender has no effect on learning motivation.

The results of analysis of covariance for the effect of the independent variable (education) on the dependent variable of academic procrastination are reported in Table 3.

Table 3. analysis of covariance to investigate the effect of education on academic procrastination

\begin{tabular}{|c|c|c|c|c|c|c|}
\hline Source & SS & df & MS & F & $p$ & Effect size \\
\hline Pre test & 1317.11 & 1 & 1317.11 & 21.04 & .001 & .33 \\
\hline Education & 1463.38 & 1 & 1463.38 & 42.44 & .001 & .55 \\
\hline Gender & 31.10 & 1 & 31.10 & 1.22 & .33 & .07 \\
\hline Interaction & 18.97 & 1 & 18.97 & 0.84 & .45 & .05 \\
\hline Error & 615.20 & 27 & 22.78 & & & \\
\hline Total & 3395 & 30 & & & & \\
\hline
\end{tabular}

As can be seen from Table 3, the pre-test of academic procrastination with a value of $\mathrm{F}=21.04$ is significant at the level of error less than 0.01. Also, the effect of the independent variable, education, on the post-test of academic procrastination has become significant $(\mathrm{F}=42.44)$. In fact, after removing the pre-test effect, the independent variable had an effect on the dependent. But gender has no effect on academic procrastination. The interactive effect is also not significant. This finding confirms the second hypothesis of the research.

\section{Discussion}

The present study compares the motivation of learning and academic procrastination of elementary students in face-to-face and virtual education. The purpose of addressing this issue is to examine and compare the two behavioral and motivational variables in face-to-face and virtual education in a situation where virtual education has expanded following the outbreak of coronavirus. To achieve this goal, two groups of elementary students who were matched in terms of the main disturbing variables are compared in two groups of 30 people who differed only in the type of received education. The results show that in virtual education compared to face-to-face education, students' learning motivation has decreased significantly. Also in face-to-face education, students are less procrastinating than in virtual education. And this difference is significant. Gender and its interactive effect with education were not significant.

Confirmation of the first hypothesis show that the motivation to learn in virtual education has significantly decreased compared to face-to-face education. But gender has no effect on learning motivation. In this regard, Rovai, Ponton, Wighting \& Baker's research (2007) show that people who attend virtual classes have more intrinsic motivation to learn, but external motivation is no different from face-to-face training group. Research by Deiz, Tras and Aydogan (2009) show that when a student is interested in a subject in face-to-face education and enjoys studying it, it increases motivation and 
spends more time learning. Rajaei Harandi (2015) also show that learning motivation is higher in virtual education. According to the findings of Ditta et al. (2020), e-learning in students' learning can increase the motivation for further learning. The results of these studies are inconsistent with the results of the present study on the effect of virtual education. The most important reason for this disparity is that in these studies, the sample people voluntarily choose virtual education and consider it in accordance with their living conditions. Obviously, when virtual education is chosen, it means that face-to-face education is not suitable for them. But the findings of Tan (2020) show that compulsory e-learning due to the outbreak of coronavirus does not increase the motivation of learners. It seems that the current situation in which virtual education has completely replaced face-to-face education, and the opportunity to benefit from face-to-face education has been minimized is comparable to the situation in which virtual education served as an option for learners. In addition, in Iran, e-learning has not been used in schools prior to the outbreak of the coronavirus and it became more difficult to adapt to. In addition to these reasons, it should be noted that the problems related to Internet infrastructure in Iran, especially in deprived areas cannot cover the vitality of the e-learning environment. Virtual education can take place in a dynamic communication environment in which, in addition to holding formal classes, students can also interact with each other. The decline in learning motivation in e-learning, which is shown in the findings of this study, is not necessarily due to e-learning and is probably limited to e-learning provided in the educational software environment in Iran. Learning motivation may be improved by strengthening this program and providing the necessary infrastructure.

Analysis and confirmation of the second hypothesis showed that procrastination in virtual education has increased significantly compared to face-to-face education. But gender has no effect on procrastination. Diz et al. (2009) show that when students study a subject without interest, it causes more academic procrastination, because they do not enjoy learning as an annoying task. According to Custer's (2016) study, anxiety is a type of performance anxiety that affects students' abilities. Solmon \& Rothblum (1984) find that academic procrastination is also significantly associated with anxiety. Anxiety and fear of failure as a source of stress increases procrastination. In the study of Islas (2018), studies have shown that boys are more procrastinating than girls. But in Custer's (2016) research, there is a relationship between gender and academic procrastination, it is disparate. Students who procrastinate feel more anxious. Delaying homework can lead to delayed unwanted feedback or other consequences of poor performance. Increasing procrastination in e-learning is also an aggravating factor. In explaining the more procrastination of students in virtual education than face-to-face education, two related factors can be mentioned. The first reason is related to the reduction of school supervision. It is more possible to monitor how homework is done and to advance academic programs in face-to-face training. Virtual education has limited the possibility of communication between the school system and the student and is the only teacher who usually has one-way communication with students. The second reason, according to Kurt Levine, is related to the students' field psychological atmosphere. Kurt Levine's field theory is based on the principle that behavior is formed by the field that exists at that moment (Seif, 2019). Students will help increase their energy and level of activity by seeing academic activities in face-toface education. But due to students's distance from each other and reduction of academic communication between classmates, the tendency of learning activities decreases and procrastination increases.

The most important limitation of the present study is its statistical population. In a statistical community of selected rural areas, the results cannot be properly reflected in a community with more cultural facilities, high social and economic status. Educational planners, especially elementary teachers, are advised to hold online classes in the most similar situation to face-to-face training to make virtual education more dynamic and attractive. To do this, you can use the video communication of the teacher and filming in the classroom. 
Conflict of interest: The authors stated no conflict of interest in the study.

Financial sponsor: The authors acknowledge that they have not received any financial support for all stages of the study, writing and publication of the paper.

\section{References}

Azlan, C. A., Wong, J. H. D., Tan, L. K., Huri, M. S. N. A., Ung, N. M., Pallath, V., ... \& Ng, K. H. (2020). Teaching and learning of postgraduate medical physics using Internet-based e-learning during the COVID-19 pandemic-A case study from Malaysia. Physica Medica, 80, 10-16.

Basco, M.R., (2010).The procrastinator's Guide to Getting Things Done. Printed in the United States of America, 72 Spring Street, New York, NY 10012.

Boice, R., (1996). Procrastination and Blocking: A Novel, Practical Approach. Printed in the United States of America.

Concepcion, A., (2020).Temporal Discounting and the Assessment and Treatment of Academic Procrastination. A dissertation submitted in partial fulfillment of the requirements for the degree of Doctor of Philosophy Degree in Applied Behavior Analysis Department of Child and Family Studies College of Behavioral and Community Sciences University of South Florida.

Custer, N.R., (2016). TEST ANXIETY AND ACADEMIC PROCRASTINATION AMONG PRELICENSURE NURSING STUDENTS A Dissertation Submitted to the School of Graduate Studies and Research in Partial Fulfillment of the Requirements for the Degree Doctor of Philosophy. Indiana University of Pennsylvania.

Deiz M, Tras Z, Aydogan D. (2009). An investigation of academic procrastination, locus of control, and emotional intelligence. J Educ Sci Theory Pract. 2009; 9:623-32.

Dhawan, Sh., (2020). Online Learning: A Panacea in the Time of COVID-19 Crisis. Journal of Educational Technology Systems 2020, Vol. 49(1) 5-22

Ditta, A. S., Strickland-Hughes, C. M., Cheung, C., \& Wu, R. (2020). Exposure to information increases motivation to learn more. Learning and Motivation, 72, 101668.

DuQuette, J.P., (2017). CYPRIS VILLAGE: LANGUAGE LEARNING IN VIRTUAL WORLDS (In Partial Fulfillment of the Requirements for the Degree of Doctor of Education). A Dissertation Submitted to the Temple University Graduate Board.

Ellis, A., \& Knaus, W.J., (1979). Overcoming Procrastination or How to Think and Act Rationally in Spite of Life's Inevitable Hassles. New York 10019.

Fandiño, F. G. E., Muñoz, L. D., \& Velandia, A. J. S. (2019). Motivation and E-Learning English as a foreign language: A qualitative study. Heliyon, 5(9), e02394.

Islas, M. S. (2018). An exploration of the triadic model of procrastination: arousal, avoidant, and decisional procrastination in adults (Doctoral dissertation).

Jaggars, S. S. (2014). Choosing between online and face-to-face courses: Community college student voices. American Journal of Distance Education, 28(1), 27-38.

Karimi Moonaghi, H., \& Baloochi Beydokhti, T. (2017). Academic procrastination and its characteristics: A Narrative Review. Future of medical education journal, 7(2), 43-50 (in Persian).

Kim, C., Park, S. W., \& Cozart, J. (2014). Affective and motivational factors of learning in online mathematics courses. British Journal of Educational Technology, 45(1), 171-185.

Kljajic, K., \& Gaudreau, P. (2018). Does it matter if students procrastinate more in some courses than in others? A multilevel perspective on procrastination and academic achievement. Learning and Instruction, 58, 193-200. 
Li, L., Gao, H., \& Xu, Y. (2020). The mediating and buffering effect of academic self-efficacy on the relationship between smartphone addiction and academic procrastination. Computers \& Education, $159,104001$.

Liu, I. F. (2020). The impact of extrinsic motivation, intrinsic motivation, and social self-efficacy on English competition participation intentions of pre-college learners: Differences between high school and vocational students in Taiwan. Learning and Motivation, 72, 101675.

Mishra, L., Gupta, T., \& Shree, A. (2020). Online teaching-learning in higher education during lockdown period of COVID-19 pandemic. International Journal of Educational Research Open, 1, 100012.

Molnar, A., Miron, G., Elgeberi, N., Barbour, M. K., Huerta, L., Shafer, S. R., \& Rice, J. K. (2019). Virtual Schools in the US 2019. National Education Policy Center.

Moqaddas Bayat, M. R. (2003). Standardization of Takman procrastination test for students. Master's Thesis, Islamic Azad University, Roodehen Branch (in Persian).

Murayama, K., FitzGibbon, L., \& Sakaki, M. (2019). Process account of curiosity and interest: A reward-learning perspective. Educational Psychology Review, 31(4), 875-895.

Oga-Baldwin, W. Q., \& Fryer, L. K. (2020). Profiles of language learning motivation: Are new and own languages different? Learning and Individual Differences, 79, 101852.

Olson, M. H. (2015). Introduction to theories of learning. Translate by aliakbar seyf, Tehran: doran. (In Persian).

Rajaei Harandi, S. R. (2015). Effects of e-learning on Students' Motivation. Procedia-Social and Behavioral Sciences, 181, 423-430.

Rovai, A., Ponton, M., Wighting, M., \& Baker, J. (2007). A comparative analysis of student motivation in traditional classroom and e-learning courses. International Journal on E-learning, 6(3), 413-432.

Samavi, S. A., Ebrahimi, K., \& Javdan, M. (2017). Relationship between academic engagements, selfefficacy and academic motivation with academic achievement among high school students in Bandar Abbas. Biquarterly Journal of Cognitive Strategies in Learning, 4(7), 71-92(in Persian).

Samavi, S. A., Javidi, H., Kazemi, S., \& Bagholi, H. (2020). Investigating the Impact of Teaching Based on Flipped Learning on the Academic Achievement of Sixth-Grade Students. Iranian Evolutionary and Educational Psychology Journal, 2(2), 89-97.

Santamaría-Bonfil, G., Ibáñez, M. B., Pérez-Ramírez, M., Arroyo-Figueroa, G., \& Martínez-Álvarez, F. (2020). Learning analytics for student modeling in virtual reality training systems: Lineworkers case. Computers \& Education, 151, 103871.

Seif, A. (2019). Modern educational psychology, Tehran: Dowran Publication (in Persian).

Singh, V., \& Thurman, A. (2019). How many ways can we define online learning? A systematic literature review of definitions of online learning (1988-2018). American Journal of Distance Education, 33(4), 289-306.

Solomon, L. J., \& Rothblum, E. D. (1984). Academic procrastination: Frequency and cognitivebehavioral correlates. Journal of Counseling Psychology, 31(4), 503-509.

Tan, C. (2020). The impact of COVID-19 on student motivation, community of inquiry and learning performance. Asian Education and Development Studies.

Tsai, C., \& Shen, P. (2009). Applying web-enabled self-regulated learning and problem-based learning with initiation to involve low-achieving students in learning. Computers in Human Behavior, 25(6), 1189-1194

Tuan, H. L., Chin, C. C., \& Shieh, S. H. (2005). The development of a questionnaire to measure students' motivation towards science learning. International journal of science education, 27(6), 639-654.

Tuckman, B. W. (1991). The development and concurrent validity of the procrastination scale. Educational and psychological measurement, 51(2), 473-480. 
Wenzlau, K. (2019). Teaching Practices: A Qualitative Case Study on the Differentiated Instructional Practices Used in Teaching in a Virtual High School Classroom (Doctoral dissertation, Grand Canyon University).

Won, S., \& Shirley, L. Y. (2018). Relations of perceived parental autonomy support and control with adolescents' academic time management and procrastination. Learning and Individual Differences, 61, 205-215.

Yu, H., Sirsat, S. A., \& Madera, J. M. (2018). Enhancing hospitality students' motivation to learn food safety knowledge using tablet personal computer (TPC)-based simulation game class activity. Journal of Hospitality, Leisure, Sport \& Tourism Education, 23, 82-94.

Ziegler, N., \& Opdenakker, M. C. (2018). The development of academic procrastination in first-year secondary education students: The link with metacognitive self-regulation, self-efficacy, and effort regulation. Learning and Individual Differences, 64, 71-82. 